\title{
Genetic Regulation of the Quinic Acid Utilization (QUT) Gene Cluster in Aspergillus nidulans
}

\author{
By SUSAN GRANT, ${ }^{1}$ C. F. ROBERTS,${ }^{1}$ HEATHER LAMB ${ }^{2}$, M. STOUT ${ }^{2}$ \\ AND A. R. HAWKINS ${ }^{2 *}$ \\ ${ }^{1}$ Department of Genetics, The University, Leicester LEI $7 R H, U K$ \\ ${ }^{2}$ Department of Genetics, The University, Newcastle upon Tyne NEI 7RU, UK
}

(Received 16 July 1987)

\begin{abstract}
A large number of quinic acid non-utilizing qut mutants of Aspergillus nidulans deficient in the induction of all three quinic acid specific enzymes have been analysed. One class, the qut $D$ mutants, are all recessive and are non-inducible at $\mathrm{pH} 6.5$ due to inferred deficiency in a quinate ion permease. Two regulatory genes have been identified. The QUTA gene encodes an activator protein since most qutA mutants are recessive and non-inducible although a few fully dominant mutants have been found. The QUTR gene encodes a repressor protein since recessive mutations are constitutive for all three enzyme activities. Rare dominant non-inducible mutants which revert readily to yield a high proportion of constitutive strains are inferred to be qut $R$ mutants defective in binding the inducer. The gene cluster has been mapped in the right arm of chromosome VIII in the order: centromere - $>50$ map units - ornB - 12 map units - qutC (dehydratase) - 0.8 map units - qut $D$ (permease), qut $B$ (dehydrogenase), qut $E$ (dehydroquinase), $q u t A$ (activator) - 4.4 map units - qut $R$ (repressor) - 20 map units - galG. This organization differs from that of the qa gene cluster in Neurospora crassa, particularly in the displacement of $q u t C$ and qut $R$.
\end{abstract}

\section{INTRODUCTION}

The initial stages in the degradation of quinic acid by Aspergillus nidulans and other fungi include two metabolic intermediates, 3-dehydroquinic acid and dehydroshikimic acid, which are also produced in the common pathway for the synthesis of aromatic amino acids. Two distinct isoenzymes interconvert these substrates and are encoded by two genes subject to different genetic and physiological controls (Hawkins et al., 1982; Kinghorn \& Hawkins, 1982; Giles et al., 1967b). One isoenzyme, biosynthetic 3-dehydroquinase, is a component of a pentafunctional polypeptide encoded by a single complex locus which is expressed at low constitutive levels (Charles et al., 1986; Giles et al., 1967a). The other isoenzyme, catabolic 3dehydroquinase, is a single-function polypeptide encoded by a gene which is a member of a cluster of tightly linked structural genes highly inducible by quinic acid and under the control of linked regulatory genes (Hawkins et al., 1982, 1984; Case \& Giles, 1975).

We wish to understand the origin of these different genetic functions in A. nidulans, and the genetic and molecular mechanisms which regulate and co-ordinate their expression and maintain physiological balance between potentially competing metabolic pathways. The $A R O M$ locus encoding the pentafunctional polypeptide has been isolated and sequenced (Kinghorn \& Hawkins, 1982; Charles et al., 1985, 1986), and strong homology has been found with the corresponding bacterial genes, suggesting common phylogenetic origin and multiple gene fusions (Hawkins, 1987).

Quinic acid is a good carbon source for A. nidulans, inducing high levels of the three enzymes 
specific for degradation to protocatechuic acid, which are encoded by three closely linked genes QUTB, dehydrogenase (EC 1.1.1.24) (1), QUTE, catabolic 3-dehydroquinase (EC 4.2.1.10) (2) and $Q U T C$, dehydratase (3). Mutations in these genes cause the loss of a single enzyme activity, and a second class of closely linked pleiotropic point mutations result in the failure to induce all three enzyme activities (Hawkins et al., 1982). The non-inducible mutants generally complement single enzyme deficient mutants in heterozygous diploids, indicating their potential to produce all three enzyme activities and trans activity of the normal gene product (Hawkins et al., 1984). Molecular analysis of the gene cluster has been initiated by the isolation of $13.2 \mathrm{~kb} A$. nidulans genomic DNA in recombinant phage $\lambda-\mathrm{Q} 1$ using the catabolic 3dehydroquinase gene $Q A-2$ of Neurospora crassa as a hybridization probe (Hawkins et al., 1985).

Previous analysis of the $Q A$ system in $N$. crassa (see Giles et al., 1985, for a recent review) has shown that three tightly linked structural genes $Q A-2(2), Q A-4$ (3) and $Q A-3(1)$ are regulated by an adjacent region $Q A-1$, in which two classes of non-inducible mutants producing slow ( $q a-1 S)$ or fast $(q a-1 F)$ complementation in heterokaryons are separately located. Molecular analysis has revealed two genes in the $Q A-1$ region (Huiet, 1984), which are interpreted to encode activator $(Q A-l F)$ and repressor $(Q A-1 S)$ proteins, and also two further quinic acid induced genes $Q A-X$ and $Q A-Y$ of unknown function (Patel $e t$ al., 1981).

This paper describes the isolation and analysis of a large number of non-inducible qut mutants in $A$. nidulans. The majority are at the QUTA locus and their various properties indicate that the QUTA gene encodes an activator protein. The isolation of constitutive mutants and their distinct properties identify a new gene $Q U T R$ encoding a repressor protein, and linked $(\mathrm{RF}=4.4 \%)$ to the $Q U T$ gene cluster.

\section{METHODS}

Strains, media, and genetic and biochemical techniques. These were as previously described (Hawkins et al., 1984).

Qualitative test for the overall reaction from quinic acid to protocatechuic acid (PCA). This was developed from the procedure described by Partridge et al. (1972). The freshly prepared reaction mixture contained 5.0 ml dimethyl sulphoxide (Spectrosol, BDH); $5.0 \mathrm{ml} \mathrm{0.4} \mathrm{M-potassium} \mathrm{glycinate} \mathrm{pH} \mathrm{9.2;5.0} \mathrm{ml} \mathrm{20 \% (w/v)} \mathrm{quinic} \mathrm{acid} \mathrm{pH} \mathrm{6.5;}$ $1.3 \mathrm{ml} 1 \%(\mathrm{w} / \mathrm{v}) \mathrm{FeCl}_{3} ; 1.0 \mathrm{ml}$ cycloheximide $\left(3 \mathrm{mg} \mathrm{ml}^{-1}\right.$ solution) $; 7.0 \mathrm{ml}$ distilled water; $5.0 \mathrm{mg}$ NAD.

Samples of mycelium in $4 \mathrm{~mm}^{3}$ blocks of agar (see below) were placed in $1 \times 6 \mathrm{~cm}$ disposable plastic tubes and $0.75 \mathrm{ml}$ reaction mixture was added. Paraffin oil was overlaid to exclude air and the tubes were incubated at $30^{\circ} \mathrm{C}$ overnight. Mycelium is permeabilized by dimethyl sulphoxide, particularly to NAD cofactor for the dehydrogenase, and PCA produced from quinic acid by the overall three enzyme activities is detected as an intense red colouration developed by complex formation with $\mathrm{Fe}^{3+}$. Atmospheric oxygen is excluded to prevent the further metabolism of PCA by oxygenase, although in the procedure described it was unnecessary and equivalent results were obtained with or without the addition of paraffin oil.

Samples of mycelium were grown from a heavy inoculum of conidiospores placed as a patch $1 \mathrm{~cm}$ diameter on the surface of minimal agar and incubated overnight at $37^{\circ} \mathrm{C}$. Mycelium should be taken in primary growth and before any sign of conidiation, when enzyme levels fall sharply. Enzyme induction was tested in mycelium grown on $40 \mathrm{~mm}$-glycerol $+0.2 \%(\mathrm{w} / \mathrm{v})$ quinic acid $\mathrm{pH} 6.5$, and constitutive enzyme production in mycelium grown on glycerol alone.

This procedure proves a highly sensitive and reliable qualitative test for the presence of enzyme activities, but can be misleading quantitatively. It has been used in an in vitro complementation reaction with mycelium of strains known to lack one of each of the three enzymes to identify qut mutant enzyme deficiences, to isolate and analyse constitutive mutants and to test for dominance in heterozygous diploids.

Reversion of qut non-inducible mutants. Spores were plated (approximately $10^{6}$ per dish) on defined medium with quinic acid at pH $6.5(1 \%, \mathrm{w} / \mathrm{v})$ as carbon source, briefly exposed to UV light at a dose permitting $75 \%$ survival, and incubated for up to $4 \mathrm{~d}$. Very few colonies appeared for strains plated without irradiation, indicating the stability of the mutant alleles. Revertant strains recovered after irradiation were tested for growth on quinic acid and constitutive enzyme formation was examined by use of the qualitative test following growth on glycerol minimal agar.

\section{RESULTS}

\section{Isolation and analysis of further non-inducible qut mutants}

A large number of new mutant strains unable to utilize quinic acid as sole carbon source for growth were isolated by filtration-enrichment (Armitt et al., 1976). These mutants represent 
lesions in the metabolism of quinic acid to tricarboxylic acid (TCA) cycle intermediates and in the gluconeogenic metabolism of these intermediates for biosynthesis. Mutant strains deficient in gluconeogenesis were identified by their failure to utilize acetate for growth (Armitt et al., 1976). The remaining mutant strains may have lesions in the uptake or metabolism of quinic acid to protocatechuic acid (PCA) or in the further metabolism of PCA to TCA cycle intermediates, and these two classes were separated by the qualitative test for the overall reaction from quinic acid to PCA. This procedure identified 140 specific quinate non-utilization (qut) mutants and 168 mutants deficient in the further metabolism of PCA. Some of the latter mutants showed an immediate strong positive reaction when mycelium grown on glycerol and quinate was tested, indicating the accumulation of PCA due to deficiency in PCA oxygenase.

The further characterization of the specific quinic acid non-utilization (qut) mutants was based upon a second application of the qualitative test in an in vitro enzyme complementation procedure. Samples of quinate-induced mycelium of three mutant strains each known to lack a single enzyme (qutB42, dehydrogenase; qutE208, catabolic 3-dehydroquinase; qutC119, dehydratase), were separately combined with quinate-induced mycelium of each of the new qut mutants in the reaction system. A series of reconstruction experiments showed that induced mycelium of the known mutants with different single enzyme deficiencies complemented one another to complete the overall reaction and produce PCA from quinic acid. The combination of mutants with the same enzyme deficiency did not yield significant PCA formation and mycelium of induced mutant strains did not inhibit the production of PCA by induced mycelium of wild-type controls. Interestingly, mycelium of the previously identified non-inducible mutant strains qut A4 and qutD8 (Hawkins et al., 1984) yielded no PCA formation in the qualitative test, even after prolonged incubation of the samples either separately or together, and did not prevent PCA production by wild-type induced mycelium. Finally, and as expected, no PCA was detected when mycelium of qutA4 and qutD8 grown in the presence of quinic acid was combined with induced mycelium of each of the single enzyme deficient mutant strains described above. Thus the characteristic inability of non-inducible mutants to produce all three of the quinic acid specific enzyme activities can be demonstrated by the in vitro enzyme complementation technique.

One half (65) of the new qut mutants were non-inducible for all three enzyme activities. Some mutants could not be resolved, either due to a 'leaky' phenotype in the qualitative test or to ambiguous reactions with the known strains, but the loss of a single enzyme activity in the remaining mutants ( 31 qutB and $17 q u t C$ ) was identified with confidence. Five new qutE mutants deficient in catabolic 3-dehydroquinase were found. These mutants, like qutE208, were leaky in the qualitative test due to the presence of the isoenzyme biosynthetic 3-dehydroquinase, but gave a strong positive result when combined with $q u t B$ and qutC mutant strains. Since our major interest was the acquisition of further non-inducible mutant strains, the new qut mutants with apparent single enzyme deficiencies were not characterized further.

A small number of non-inducible mutants were assayed for the three quinate specific enzyme activities following transfer of glucose-grown mycelium to quinic acid growth medium of pH 6.5. None of the five strains examined (qut314, 312, 331, 303 and 365) contained any detectable activity of each of the three enzymes. Two other strains (qut434, 435) which were subsequently found non-complementary to qutB42 in heterozygous diploid strains also lacked dehydrogenase activity.

Analysis of the non-inducible qut mutant strains. Complementation analysis in heterozygous diploid strains was used to characterize the new non-inducible qut mutants, and the data confirmed the value of the qualitative test in the classification of mutants by the in vitro enzyme complementation procedure. A few of the new qut strains ( 5 in 74) were not fully resolved, and the possibility that these are $q u t E$ or $q u t C$ mutants has not been tested. A further 7 strains proved to be qut $B$ mutants, and thus the accuracy of the qualitative test in the identification of noninducible qut mutants was over $80 \%(62$ in 74$)$. All of the seven qut $B$ and five possible $q u t E$ or qutC mutants were recessive to wild-type.

Amongst 65 non-inducible mutants, 9 contained recessive alleles at the qutD locus. These 
mutants did not grow on quinic acid media at pH 6.5 but all grew normally on quinic acid when tested at $\mathrm{pH} 3.5$ and produced all three quinic acid specific enzyme activities when induced at this $\mathrm{pH}$. This result strongly suggested that $Q U T D$ encodes an essential component of a permease required to transport quinate ion into mycelium from media at $\mathrm{pH} 6.5$ (Whittington et al., 1987).

The remaining 56 non-inducible mutants proved of particular interest with respect to their dominance. A minority (including qut $A 303$ ) appeared fully recessive, since when combined with wild-type $(Q U T)$ and the qutD8 or qutB42 mutant strains, the resulting heterozygous diploids exhibited full wild-type growth. The recessive mutants yielded heterozygous diploids with qutA4 which failed to grow on quinic acid and are therefore identified as qut $A$ alleles. The majority of the mutants exhibited partial dominance and growth on quinic acid of heterozygous diploids with wild-type ( $Q U T)$, qutD8 or qutB42 was poor compared to wild-type, but stronger than that of homozygous double mutant strains or of the haploid mutant strains. This phenotype is characteristic of the qutA4 mutant and all of these partially dominant mutants yielded heterozygous diploids with qut $A 4$ which failed to grow on quinic acid. Thus the majority of the new non-inducible qut strains are identified as qut $A$ mutants.

A minority of non-inducible qut mutants (qut 341, 365, 373, 382, 405) together with one mutant (qut214) isolated previously (Hawkins et al., 1985) appeared fully dominant since heterozygous diploid strains with wild-type $(Q U T)$, or any other qut mutant strain, did not grow on quinic acid medium. The dominance of qut 341 and qut 365 was confirmed by the absence of all three enzyme activities in heterozygous diploid strains (data not shown).

Recombination analysis of the dominant non-inducible qut mutants. The majority of noninducible mutants isolated exhibit a degree of dominance in heterozygous diploid strains and are functionally allelic to qut $A$, and therefore it seemed likely that the dominant mutations may also be at the qut $A$ locus. This was tested by crossing the dominant mutants to a recessive mutant: qut $A 303$ and selecting for prototrophic $Q U T$ recombinants on quinic acid medium. Three of the dominant non-inducible mutants (qut $214,341,382)$ were found very tightly linked (RF $0.05 \%$ or less) to qut $A 303$ but three others (qut $365,373,405$ ) recombined at a readily detectable rate (RF $2.5 \%$ ) and thus are at sites outside the QUTA gene locus. Two of these mutants (qut 365 and qut373) were mapped 4.6 and 5.0 units respectively from qutD 8 and to the right of QUTA (see Fig. 1). Further properties of these dominant non-inducible mutants which strongly suggest their location in QUTR are described below.

Reversion of non-inducible qut mutant strains and the isolation and analysis of constitutive mutant strains

The initial interpretation of $Q U T A$ in $A$. nidulans was a repressor gene equivalent to $Q A-1 S$ in $N$. crassa, and that of $Q U T D$ an activator gene equivalent to $Q A-1 F$ (Hawkins et al., 1984). Work in the $N$. crassa $Q A$ system has shown that a high proportion of prototrophic $Q A$ revertants of non-inducible qa-lS mutant strains selected by growth on quinic acid are constitutive mutants, and that such mutants were not found amongst $q a-I F$ revertants (Giles $e t$ al., 1985). We therefore attempted to isolate constitutive mutants in $A$. nidulans following the same strategy and reverting qutA mutant strains. Altogether 150 revertants of the partial dominant mutant qutA4, 250 revertants of the dominant mutant qut 214 and 100 revertants of various recessive mutants (qut $A 303,324,361,444$ ) were screened, and only a single constitutive strain was found. A small number of revertants of qutD312 were isolated and two constitutive strains recovered amongst 30 examined.

Analysis of the single constitutive revertant obtained in a qutA strain (qutA4 r3) proved complex and will be described in detail elsewhere. The constitutive phenotype is conferred by a non-allele-specific unlinked recessive suppressor of qutA mutations. The suppressor is not effective when combined with the dominant mutation qutA214 and does not confer constitutivity in a wild-type $(Q U T A)$ strain.

Reversion of qutD mutant strains and the identification of a linked repressor gene, QUTR. Following the unexpected observation that reversion of qutD312 yielded constitutive strains, 
Table 1. Identification of the repressor gene qut $R$ in $A$. nidulans

The wild-type strain in the first cross was R21 (pabaAl yA) and in the test crosses rec6 (pyroA4; qutR16) was also crossed to $\mathrm{R} 21$ and $\operatorname{rec} 86$ ( $y A$; pyro $A 4$; qutR 16$)$ was crossed to $\mathrm{R} 10($ biAl; wA3; galAI). The pooled data include those for qutD312 r16 and a series of further crosses between R21 and the constitutive revertant strains qutD312 r35, qutD $8 \mathrm{rl}$, qutD331 18 and qutD439 r3.

\begin{tabular}{|c|c|c|c|c|c|c|}
\hline \multirow[b]{2}{*}{ Cross } & \multirow[b]{2}{*}{$\begin{array}{c}\text { Classes of } \\
\text { progeny }\end{array}$} & \multicolumn{2}{|c|}{ Phenotype } & \multicolumn{2}{|c|}{ No. of progeny } & \multirow[b]{2}{*}{ Genotype } \\
\hline & & $\begin{array}{l}\text { Growth on } \\
\text { quinic acid }\end{array}$ & $\begin{array}{c}\text { Enzyme } \\
\text { formation }\end{array}$ & rl6 & $\begin{array}{l}\text { Pooled } \\
\text { data }\end{array}$ & \\
\hline $\begin{array}{l}\text { qutD312 r16 } \\
\times \text { wild-type }\end{array}$ & $\begin{array}{l}\text { 1. Wild-type } \\
\text { 2. qutD312 r16 } \\
\text { 3. qutD312 } \\
\text { 4. }\end{array}$ & $\begin{array}{c}+++ \\
(+) \\
- \\
+++\end{array}$ & $\begin{array}{l}\text { Inducible } \\
\text { Constitutive } \\
\text { Non-inducible } \\
\text { Constitutive }\end{array}$ & $\begin{array}{r}68 \\
63 \\
2 \\
4 \\
137\end{array}$ & $\begin{array}{r}293 \\
251 \\
5 \\
10 \\
559\end{array}$ & $\begin{array}{l}\mathbf{P} Q U T D \text { QUTR } \\
\mathbf{P} \text { qutD312 qutR } 16 \\
\mathrm{R} \text { qutD312 QUTR } \\
\mathrm{R} Q U T D \text { qutRI6 }\end{array}$ \\
\hline $\begin{array}{l}\text { Test crosses } \\
\text { Class } 4 \text { (rec6; rec } 86) \\
\times \text { wild-type }\end{array}$ & & $\begin{array}{l}+++ \\
+++\end{array}$ & $\begin{array}{l}\text { Inducible } \\
\text { Constitutive }\end{array}$ & $\begin{array}{r}\text { rec6 } \\
23 \\
27 \\
-50\end{array}$ & $\begin{array}{c}\text { rec86 } \\
40 \\
32 \\
\overline{72}\end{array}$ & $\begin{array}{ll}\text { QUTD } & \text { QUTR } \\
\text { QUTD } & \text { qutRI6 }\end{array}$ \\
\hline
\end{tabular}

further revertants of a series of qutD mutants ( $q u t D 8,312,331,436,439)$ were selected and a high proportion of constitutive strains recovered, 181 in 321 revertants tested. The constitutive strains all had similar phenotypes, growing very poorly on quinic acid, although mycelium grown on glycerol produced a strong positive reaction in the qualitative test, indicating substantial levels of enzymes for the overall reaction from quinic acid to PCA. In marked contrast, strongly growing revertants were not constitutive and growth in the presence of quinic acid was required to induce enzyme activities. These strains probably result from back-mutation at the qutD locus.

In order to establish the genetic basis for constitutive enzyme formation, one of the constitutive revertant strains (qutD312 r16) was crossed with wild-type and the progeny examined for growth on quinic acid and for enzyme formation using the qualitative test (Table 1). The data show that the revertant was a double mutant and the second mutation identified a new gene locus qut $R$ which controls induction of the three specific quinic acid enzymes and is closely linked to qut $D$. The constitutive mutation is fully recessive since a heterozygous diploid ( $q u t R 16 / Q U T R$ ) showed no trace of overall enzyme activity in the qualitative test when grown in the absence of quinic acid. A further 16 recessive constitutive mutants combined with a qutRl6 produced diploid strains which grew normally on quinic acid and exhibited the constitutive mutant phenotype. Thus, each of the constitutive revertant strains tested contains a new mutation functionally allelic to qutRI6.

In summary, analysis of the constitutive revertants has shown that the constitutive phenotype results from a recessive mutation in the gene qut $R$ which is linked to the $Q U T$ gene cluster. Since recessive mutations confer a loss of repression the $Q U T R$ gene is interpreted to encode a repressor protein and is formally designated $Q U T R$, quinic acid $u$ tilization repressor.

Reversion of the linked dominant non-inducible strains. Prototrophic (QUT) revertants of the strain qut365, which maps to the qut $R$ locus, were selected by plating suspensions of conidiospores on quinic acid medium. The strain reverted spontaneously at a high rate (45 QUT colonies from $10^{6}$ spores) and this rate was increased by exposure to a low dose of UV irradiation (150 colonies from $10^{6}$ spores). Revertants were screened for enzyme formation in the qualitative test following growth on glycerol and a high proportion $(95 \%)$ found constitutive. It remains to be established that the mutations conferring constitutivity are at second sites which map close to the original dominant mutation. However, the properties of the dominant mutant in its instability and in yielding a high frequency of constitutive revertants are exactly the same as the repressor $q a-1 S^{-}$and $q a-1 S^{\mathrm{c}}$ strain in $N$. crassa (Giles et al., 1985), encouraging the provisional conclusion that they are in the repressor gene locus QUTR in A. nidulans. 
Table 2. Effect of the constitutive mutation qutR16 upon enzyme formation in A. nidulans

Mycelium grown in liquid culture for $16 \mathrm{~h}$ at $37^{\circ} \mathrm{C}$ in $20 \mathrm{~mm}$-glucose was harvested aseptically by filtration and the pad rinsed with warm medium without carbon source. Each pad of mycelium was divided and samples were transferred to fresh warm growth media containing the carbon sources indicated. The cultures were incubated for a further $5 \mathrm{~h}$ at $37^{\circ} \mathrm{C}$, then mycelium was harvested, and the pad washed in extraction buffer and stored at $-20^{\circ} \mathrm{C}$ until cell-free extracts were prepared (see Methods).

\begin{tabular}{|c|c|c|c|c|c|}
\hline \multirow[b]{2}{*}{ Strain } & \multirow[b]{2}{*}{ Genotype } & \multirow[b]{2}{*}{$\begin{array}{l}\text { Glucose-grown mycelium } \\
\text { transferred to*: }\end{array}$} & \multicolumn{3}{|c|}{ Relative enzyme specific activity $\dagger$} \\
\hline & & & $\begin{array}{l}\text { Dehydrogenase } \\
\text { (1) }\end{array}$ & $\begin{array}{l}\text { Dehydroquinase } \\
\text { (2) }\end{array}$ & $\begin{array}{c}\text { Dehydratase } \\
\text { (3) }\end{array}$ \\
\hline Wild-type & $Q U T D Q U T R$ & $\begin{array}{l}\text { Quinic acid } \\
\text { Glycerol + quinic acid } \\
\text { Glycerol } \\
\text { Glucose + quinic acid } \\
\text { Glucose }\end{array}$ & $\begin{array}{l}1.00(0.25) \\
0.60 \\
0.04 \\
0.16 \\
\quad 0\end{array}$ & $\begin{array}{l}1.00(38 \cdot 8) \\
0.55 \\
0.02 \\
0.07 \\
\quad 0\end{array}$ & $\begin{array}{l}1.00(0.17) \\
1.00 \\
0 \\
0.18 \\
0\end{array}$ \\
\hline $\begin{array}{l}\text { Wild-type } \\
\text { qutD312 } \\
\text { qutD312 r16 }\end{array}$ & $\begin{array}{l}\text { QUTD QUTR } \\
\text { qutD3I2 QUTR } \\
\text { qutD312 qutR16 }\end{array}$ & $\begin{array}{l}\text { Quinic acid } \\
\text { All conditions } \\
\text { Quinic acid } \\
\text { Glycerol + quinic acid } \\
\text { Glycerol } \\
\text { Glucose + quinic acid } \\
\text { Glucose }\end{array}$ & $\begin{array}{l}1.00(0.27) \\
\\
0.74 \\
1.19 \\
1.11 \\
0.74 \\
0.52\end{array}$ & $\begin{array}{l}1.00(35 \cdot 8) \\
\text { zyme activity fc } \\
2.42 \\
1.50 \\
2.12 \\
0.91 \\
0.68\end{array}$ & $\begin{array}{l}1 \cdot 00(0 \cdot 14) \\
d \\
5 \cdot 57 \\
2 \cdot 86 \\
3 \cdot 36 \\
1 \cdot 43 \\
1 \cdot 00\end{array}$ \\
\hline $\begin{array}{l}\text { Wild-type } \\
\text { rec6(Table 1) }\end{array}$ & $\begin{array}{l}\text { QUTD QUTR } \\
\text { QUTD qutRl6 }\end{array}$ & $\begin{array}{l}\text { Quinic acid } \\
\text { Quinic acid } \\
\text { Glycerol + quinic acid } \\
\text { Glycerol } \\
\text { Glucose + quinic acid } \\
\text { Glucose }\end{array}$ & $\begin{array}{l}1 \cdot 00(0 \cdot 29) \\
1.28 \\
1.28 \\
1.31 \\
0.72 \\
0.55\end{array}$ & $\begin{array}{l}1.00(46 \cdot 2) \\
0 \cdot 88 \\
0 \cdot 85 \\
1.44 \\
0.55 \\
0.45\end{array}$ & $\begin{array}{l}1 \cdot 00(0 \cdot 27) \\
0 \cdot 74 \\
1 \cdot 19 \\
2 \cdot 30 \\
0 \cdot 78 \\
0 \cdot 67\end{array}$ \\
\hline
\end{tabular}

* The concentrations of carbon sources were: quinic acid $\mathrm{pH} 6.5,0.5 \%(\mathrm{w} / \mathrm{v})$; glycerol, $40 \mathrm{~mm}$, or glucose, $20 \mathrm{mM}$, alone or with quinic acid $\mathrm{pH} 6.5$ at $0.2 \%(\mathrm{w} / \mathrm{v})$.

$\dagger$ Relative enzyme specific activities are shown as the fraction of each of the specific activities in a quinategrown wild-type control strain $\mathrm{R} 153$ ( $w A 3$; pyroA4). Each block of results represents a particular set of experiments which included the induced wild-type control strain. Enzyme specific activities (for the absolute values shown in parentheses for the wild-type) are expressed as follows: (1) dehydrogenase, $\mu$ mol product $\min ^{-1}$ (mg protein) $)^{-1}$; (2) catabolic dehydroquinase (extract heated at $70^{\circ} \mathrm{C}$ for $10 \mathrm{~min}$ to inactivate the biosynthetic isoenzyme), units $\mathrm{mg}^{-1}$ (1 unit is a $\Delta A_{240}$ of 0.1 per min at $37^{\circ} \mathrm{C}$ ); (3) dehydratase, $\mu$ mol product $\mathrm{min}^{-1} \mathrm{mg}^{-1}$.

\section{Control of quinic acid specific enzyme formation}

Catabolite repression. Induction of the quinic acid specific enzymes in wild-type is diminished when alternative carbon sources are present in growth medium with quinic acid (Hawkins et al., 1984). The possibility that compounds such as glucose decrease induction by preventing the uptake of quinic acid into mycelium was tested by growth of mycelium of a permease mutant qut $D 8$ on glucose followed by induction on quinic acid at $\mathrm{pH} 3.5$. In this situation no permease function is required for the uptake of quinic acid and the quinate dehydrogenase was $50 \%$ repressed and the catabolic 3-dehydroquinase and dehydratase were fully repressed (data not shown). It was also found that enzyme formation was partially repressed by glucose in qut $R$ constitutive strains (Table 2). These observations confirm that enzyme induction by quinic acid is subject to a second level of control by carbon catabolite repression when alternative carbon sources such as glucose are present in the growth medium. They strongly suggest that catabolite repression is not exerted in the uptake of quinic acid but occurs within the mycelium where it is presumably mediated by the concentration of cAMP (Pall, 1981).

Constitutive expression of the quinic acid specific enzymes in qutRI6 strains. The mutation qut RI6 conferred constitutive expression of high levels of each of the three specific quinic acid enzyme activities when strains were grown in the absence of quinic acid (Table 2). Growth in the presence of quinic acid did not greatly increase enzyme levels compared to those on glycerol 


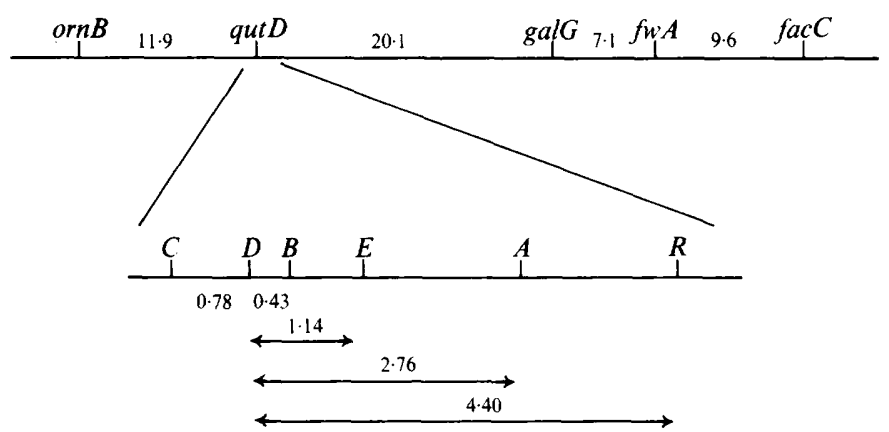

Fig. 1. The map of the qut gene cluster is from data in Table 3. The cluster was mapped in chromosome VIII in a cross between qutD312 qutR 16 and a strain containing galG2 fwAI acuC 307 from which 500 progeny were analysed (data not shown). A recombinant qutD qutR galG fwA was crossed with an ornB strain and 300 progeny were scored (data not shown). Selection of $O R N B Q U T D$ recombinants from the second cross enables deduction of the gene order:

\begin{tabular}{llllll}
+ & qutD & qutR & galG & $f w A$ \\
\hline ornB & + & & + & + & +
\end{tabular}

The distribution of the non-selected markers in 212 recombinants taken at random and a further 44 $f w A$ recombinants was:

$\begin{array}{ccccc}q u t R & \text { galG } & f w A & \begin{array}{c}\text { All } \\ \text { recombinants }\end{array} & \begin{array}{c}f w A \\ \text { recombinants }\end{array} \\ - & - & - & 6 & 3 \\ - & - & + & 0 & - \\ - & + & - & 0 & 1 \\ - & + & + & 0 & - \\ + & - & - & 23 & - \\ + & - & + & 5 & 14 \\ + & + & - & 7 & - \\ + & + & + & 171 & -\end{array}$

Thus the majority of recombinants were non-constitutive (QUTR) and all of the constitutive (qutR) recombinants were also $\mathrm{galG}$ and $f w A$. The predicted proportion of constitutive recombinants is 4.4 in 100 , of which the majority are expected $f w A$, and amongst $f w A$ recombinants 4 in 25 are expected constitutive. If the $Q U T R$ locus were between $O R N B$ and $Q U T D$ the predicted proportion of constitutive recombinants would be 4 in 12 .

alone, indicating that the mutation fully derepresses quinic acid mediated gene expression. The presence of high enzyme levels in the revertant strain qutD312 qutR16 contrasts strongly with the very poor growth produced by the strain on quinic acid, and argues that growth is limited by the defect in quinic acid uptake resulting from the qutD mutation. Failure of qutD mutants to induce enzyme activities can therefore be understood since quinic acid does not enter the mycelium at a sufficient rate to become an effective inducer (Whittington et al., 1987).

Fine-structure mapping of the QUT gene cluster

Previous work has established that the $Q U T$ genes are tightly linked in a cluster on chromosome VIII in $A$. nidulans (Hawkins et al., 1982). The isolation of the constitutive mutation qutR16 in the double mutant strain qutD312qutR16 therefore presented an opportunity to map the genes in the cluster by three-point crosses using the qutR16 mutation as a flanking marker. The distribution of the constitutive marker qutR16 in the $Q U T$ recombinants orders the $Q U T$ genes with respect to $q u t D$ and $q u t R$. The data map qutC distal to qutD with 


\section{Table 3. Fine-structure mapping of the QUT gene cluster in A. nidulans}

The double mutant strain qutD312 qutR16 was crossed with each of the qut single mutants and suspensions of ascospores from single hybrid cleistothecia were plated on glucose medium to estimate the viable count and on quinic acid medium to select prototrophic $Q U T$ recombinants. The distribution of the qut $R$ marker in a random sample of the $Q U T$ recombinants was determined using the qualitative test on glycerol-grown mycelium. In each cross two or more cleistothecia were analysed and certain crosses were repeated with different alleles at the third qut gene locus. The numbers of $Q U T$ recombinants were multiplied by two, on the argument of symmetry of reciprocal classes in inter-genic crosses, to provide an estimate of the RF between $Q U T D$ and each of the $Q U T$ genes.

\begin{tabular}{|c|c|c|c|c|c|c|c|c|}
\hline \multirow{2}{*}{\multicolumn{2}{|c|}{$\begin{array}{l}\text { Third qut } \\
\text { gene in } \\
\text { the cross }\end{array}$}} & \multirow{2}{*}{$\begin{array}{c}10^{-3} \times \\
\text { Total } \\
\text { progeny } \\
\text { tested }\end{array}$} & \multirow[b]{2}{*}{$\begin{array}{l}\text { Total } \\
\text { recombinant } \\
\text { progeny }\end{array}$} & \multicolumn{5}{|c|}{ Phenotype of $Q U T$ recombinants } \\
\hline & & & & $\begin{array}{l}\text { RF } \\
(\%)\end{array}$ & $\begin{array}{c}\text { Inducible } \\
Q U T R\end{array}$ & $\begin{array}{c}\text { Constitutive } \\
q u t R^{-}\end{array}$ & $\begin{array}{c}\text { Total } \\
\text { tested }\end{array}$ & $\begin{array}{l}\text { Gene } \\
\text { order }\end{array}$ \\
\hline \multicolumn{2}{|c|}{ qutA3031 } & $36 \cdot 0$ & 1400 & $3 \cdot 89$ & 1 & 49 & 50 & \\
\hline & 2 & $53 \cdot 6$ & 1544 & 2.88 & 1 & 51 & 52 & \\
\hline \multirow[t]{3}{*}{ qut $A 4$} & 1 & $12 \cdot 4$ & 448 & $3 \cdot 61$ & 0 & 50 & 50 & \\
\hline & 2 & $43 \cdot 6$ & 624 & 1.43 & 0 & 52 & 52 & \\
\hline & & $145 \cdot 6$ & 4016 & $2 \cdot 76$ & 2 & 202 & 204 & $D-A-R$ \\
\hline \multirow[t]{4}{*}{$q u t B 42$} & 1 & $84 \cdot 8$ & 304 & $0 \cdot 36$ & 11 & 26 & 37 & \\
\hline & 2 & $37 \cdot 7$ & 324 & 0.86 & 3 & 26 & 29 & \\
\hline & 3 & $142 \cdot 0$ & 504 & $0 \cdot 35$ & 7 & 25 & 32 & \\
\hline & & $264 \cdot 5$ & 1132 & 0.43 & 21 & 77 & 98 & $D-B-R$ \\
\hline \multirow{2}{*}{\multicolumn{2}{|c|}{$q u t C 1131$}} & $67 \cdot 2$ & 808 & $1 \cdot 20$ & 55 & 2 & 57 & \\
\hline & & $32 \cdot 5$ & 448 & $1 \cdot 38$ & 41 & 13 & 54 & \\
\hline \multirow{3}{*}{ qutC 119} & 1 & $205 \cdot 8$ & 416 & $0 \cdot 20$ & 50 & 4 & 54 & \\
\hline & 2 & 62.9 & 1210 & 1.92 & 43 & 5 & 48 & \\
\hline & & 368.4 & 2882 & 0.78 & 189 & 24 & 213 & $C-D-R$ \\
\hline \multirow{3}{*}{$q u t E 208$} & 1 & $54 \cdot 2$ & 544 & 1.00 & 0 & 50 & 50 & \\
\hline & 2 & $126 \cdot 8$ & 1520 & $1 \cdot 20$ & 2 & 48 & 50 & \\
\hline & & $181 \cdot 0$ & 2064 & $1 \cdot 14$ & 2 & 98 & 100 & $D-E-R$ \\
\hline
\end{tabular}

respect to $q u t R$, and place $q u t A, q u t B$ and $q u t E$ in the interval between the two markers. The RF values unambiguously order the genes in the sequence qutD, qutB, qutE, qutA and qutR (Table 3, Fig. 1).

The striking result is the location of QUTC. Previous work had indicated the location of QUTC between QUTB and QUTE on the basis of the hybridization of defined N. crassa $Q A$ gene probes to $A$. nidulans DNA cloned in recombinant phage $\lambda-Q 1$ (Hawkins et al., 1985). This result is not consistent with the genetic data described above and DNA sequences in $\lambda-\mathrm{Q} 1$ or any derived sub-clone do not transform qutC mutants, although qut $E$, qut $D$, qutB and qutA mutants are transformed to wild-type (Francisco Da Silva et al., 1986; Whittington et al., 1987; Beri et al., 1987; A. R. Hawkins and others, unpublished). Taken together these data are consistent with the physical presence and biological integrity of the $A$. nidulans genes $Q U T D, Q U T B$, $Q U T E$ and $Q U T A$ in the $\lambda-\mathrm{Q} 1$ clone and in an order which correlated precisely with that derived by genetic mapping.

Mapping the qut gene cluster in linkage group VIII. Crosses between the double mutant strain qutD312 qutR16 and strains with a series of markers in chromosome VIII accurately map the cluster within the chromosome (Fig. 1). The orientation of the cluster on chromosome VIII was determined by selection of $O R N B Q U T D$ recombinants from a cross between an ornB7 strain and a strain qutD312 qutRl6 galG2 fwAl and analysis of the distribution of the qutR, galG and fwA markers (Fig. 1). 
Table 4. Enzyme formation in heterozygous diploid strains

\begin{abstract}
A series of recombinant strains, denoted qutA4-1 to -8 and qutB42-1 to -8 , were isolated in the genotypic backgrounds R153 $w A 3$; pyroA4 or R21 pabaAl yA from crosses between the original mutant strains R21 qutA4 or R21 qutB42 and R153. Diploid strains heterozygous for qutA4 and qutB42 were constructed between these recombinants as shown in the table. Each of the diploid strains was grown in liquid culture with glucose as a carbon source following the protocol described in Table 2 and transferred to fresh growth medium with $0.1 \%(\mathrm{w} / \mathrm{v})$ quinic acid at $\mathrm{pH} 6.5$ and incubated for a further $5 \mathrm{~h}$. Mycelium was harvested, cell-free extracts were prepared and enzyme was assayed as described in Table 2 except that the extracts were dialysed against $10 \mathrm{~mm}$-potassium phosphate buffer $\mathrm{pH} 7 \cdot 2,1 \mathrm{~mm}$ EDTA for $3 \mathrm{~h}$ before assay. Each block of results refers to a group of diploid strains treated strictly in parallel together with different cultures of the same wild-type diploid strain (R153/R21). Units of specific enzyme activity are defined in Table 2.
\end{abstract}

\begin{tabular}{|c|c|c|c|c|c|}
\hline \multicolumn{3}{|c|}{ Heterozygous diploid strains } & \multicolumn{3}{|c|}{ Enzyme specific activities } \\
\hline \multirow{2}{*}{$\begin{array}{l}\text { Serial } \\
\text { no. }\end{array}$} & \multicolumn{2}{|c|}{ Genotype } & \multirow{2}{*}{$\begin{array}{c}\text { Dehydrogenase } \\
\text { (1) }\end{array}$} & \multirow{2}{*}{$\begin{array}{c}\text { Dehydroquinase } \\
\text { (2) }\end{array}$} & \multirow{2}{*}{$\begin{array}{c}\text { Dehydratase } \\
\text { (3) }\end{array}$} \\
\hline & R 153 & R21 & & & \\
\hline WT (1) & $Q U T$ & $Q U T$ & 0.47 & 84.4 & 0.43 \\
\hline 1 & qutB42-1 & qut $A 4-8$ & $0 \cdot 26$ & $91 \cdot 2$ & 0.45 \\
\hline 2 & $q u t B 42-I$ & $q u t A 4-7$ & $0 \cdot 21$ & $77 \cdot 6$ & $0 \cdot 35$ \\
\hline 3 & $q u t B 42-1$ & $q u t A 4-6$ & 0.23 & 93.8 & 0.42 \\
\hline WT (2) & $Q U T$ & $Q U T$ & $0 \cdot 31$ & $112 \cdot 0$ & 0.27 \\
\hline 5 & qut $B 42-2$ & qutA4-5 & $0 \cdot 18$ & 117.0 & 0.40 \\
\hline 6 & $q u t B 42-3$ & qut $A 4-5$ & 0.13 & $78 \cdot 3$ & $0 \cdot 27$ \\
\hline 7 & $q u t B 42-4$ & $q u t A 4-5$ & $0 \cdot 15$ & $97 \cdot 1$ & 0.27 \\
\hline 8 & qut $A 4-3$ & qutB42-5 & 0.20 & $100 \cdot 0$ & 0.33 \\
\hline WT (3) & $Q U T$ & $Q U T$ & 0.53 & $77 \cdot 1$ & 0.50 \\
\hline 9 & $q u t A 4-2$ & $q u t B 42-5$ & $0 \cdot 20$ & 58.8 & 0.47 \\
\hline 10 & $q u t A 4-I$ & $q u t B 42-5$ & $0 \cdot 19$ & $54 \cdot 4$ & 0.35 \\
\hline 11 & qut A4-1 & qut $A 42-6$ & 0.24 & $62 \cdot 5$ & 0.42 \\
\hline 12 & qut A4-1 & $q u t B 42-7$ & $0 \cdot 23$ & $71 \cdot 0$ & 0.50 \\
\hline WT (4) & $Q U T$ & $Q U T$ & 0.58 & $97 \cdot 0$ & 0.20 \\
\hline 4 & qutB4-21 & qut $A 4-5$ & $0 \cdot 16$ & 78.0 & 0.17 \\
\hline 13 & qutA4-I & $q u t B 42-8$ & 0.21 & $64 \cdot 0$ & $0 \cdot 18$ \\
\hline
\end{tabular}

Enzyme formation in heterozygous diploid strains

In wishing to study potential gene interactions in heterozygous diploid strains we thought it essential to establish that the enzyme levels induced by quinic acid reflect the specific $Q U T$ genotype of strains investigated and are not subject to variation caused by unidentified modifying factors in the genetic background. In order to test this hypothesis, enzyme levels were measured in a series of heterozygous diploid strains constructed between different haploid recombinant strains isolated from sexual crosses and carrying the qut $A 4$ or qutB42 mutant alleles in the complementary genotypes (Table 4). The data were subjected to an unbalanced analysis of variance using the methods of Baker \& Nelder (1978). The statistical analysis (not shown) indicated that the activity of quinate dehydrogenase in heterozygous diploids (qutB42/QUTB) has a highly significant difference from that in the homozygous diploid $(Q U T B / Q U T B)$ as is expected for a mutant strain, and that the reduced levels do not differ if the qutB42 mutant allele is in the R21 or R153 genetic backgrounds. Moreover, when the non-inducible catabolic qut A4 mutation is in either the R21 or the R153 background the activities of catabolic 3dehydroquinase (2) and dehydratase (3) in heterozygous diploids (qutA4/QUTA) do not differ significantly from the homozygous diploid (QUTA/QUTA) control. Overall, the analysis shows that there is no major contribution to variance from potential modifying genes segregating in the genetic background and that the phenotypes observed can be directly attributed to the $Q U T$ genotypes. 


\section{DISCUSSION}

This paper identifies genes regulating expression of the quinic acid utilization $(Q U T)$ gene cluster in Aspergillus nidulans and extends the model previously proposed in which two genes regulate expression of the enzyme structural genes (Hawkins et al., 1984). Recessive noninducible mutants at the $Q U T A$ locus identify the gene as normally having a positive role, activating the expression of the structural genes. Recessive constitutive mutants have identified a new gene locus QUTR distinct from QUTA and the other $Q U T$ gene loci, but closely linked $(\mathrm{RF}=4.4 \%)$ to the $Q U T$ gene cluster. Thus the positively acting $Q U T A$ gene encodes an activator protein and the negatively acting $Q U T R$ gene a repressor protein. Several hypotheses can be suggested for the precise mechanism by which these two proteins may interact with each other, with the inducer and at the promoter regions of the structural genes. Rapid progress in the molecular analysis of the system will enable refinement of the model (A. R. Hawkins and others, unpublished).

The formal map of the QUT gene cluster in A. nidulans (Fig. 1) is consistent with the molecular analysis of the cloned genes (A. R. Hawkins and others, unpublished). Comparison of the genomic organization of the $Q U T$ cluster in $A$. nidulans with the corresponding $Q A$ gene cluster in Neurospora crassa (Giles et al., 1985) is therefore of interest. Both systems include five quinate inducible genes and an activator and a repressor regulatory gene. Two of the genes in N. crassa, $Q A-X$ and $Q A-Y$, have no identified function. We find that the $Q U T D$ permease gene in $A$. nidulans shows sequence homology to $Q A-Y$ in $N$. crassa (R. Geever, personal communication), supporting the deduction that $Q A-Y$ encodes a permease (Giles et al., 1985). Major differences are found between the two systems since in $A$. nidulans (Fig. 1) the QUTC gene (dehydratase $=Q A-4)$ and the repressor gene $Q U T R(=Q A-1 S)$ are displaced and map at significant distances from the other tightly linked genes. Separation of the two regulatory genes requires that each is under the control of an independent promoter whereas in $N$. crassa the two corresponding genes are transcribed from a common promoter region. It remains to be discovered if this difference in the location of the regulatory genes in $A$. nidulans may be correlated with differential physiological controls acting at each of the promoters. Previous work has demonstrated transcription control of the catabolic 3-dehydroquinase QUTE gene (Francisco Da Silva et al., 1986) and it is likely that the other structural genes are similarly controlled. The nature of the control of the two regulatory genes is currently under investigation.

Three different classes of non-inducible activator qut $A$ gene mutation have been found in $A$. nidulans based upon growth of heterozygous diploid strains on quinic acid media. In one, the diploids grow normally, enzyme activities are fully induced and the mutants are thus recessive. In a second, the diploids do not grow, enzymes are not induced and the mutants are thus fully dominant. In contrast, the majority of mutants appear partially dominant in that growth of the diploids on quinic acid is decreased. However, although induced enzyme activities appear similarly decreased in heterozygotes (Hawkins et al., 1984), statistical analysis shows that the observed values for 3-dehydroquinase and dehydratase fall within the range of variation for wild-type diploid controls (Table 4). Therefore this major class of non-inducible mutants are recessive to the wild-type ( $Q U T A)$ with respect to enzyme induction for 3-dehydroquinase and dehydratase although incompletely recessive in growth of heterozygous diploids. It is possible that the reduced growth reflects a differential effect of the qutA4 mutant gene product upon the expression of $Q U T B$ and/or $Q U T D$, and we are currently investigating this possibility. These observations are like those in $N$. crass $a$ where the non-inducible $q a-1 F$ mutants are all classified as recessive in heterokaryon tests. However, such tests are acknowledged as unsatisfactory because the precise allele ratio is unknown in the heterokaryons (Giles et al., 1985).

The repressor gene QUTR was discovered as second-site mutations in poorly growing revertants of permease deficient (qutD) strains. The constitutive mutations in qutR are fully recessive and most probably represent loss of repressor activity. The small number of noninducible dominant mutants which map consistent with their location in qut $R$ revert at a high frequency to produce constitutive mutants. The dominance and location of these presumed second-site qut $R$ mutations remain to be established, but exactly parallel the reversion of dominant mutations in the repressor gene qa-1S in $N$. crassa (Giles et al., 1985). We are actively 
pursuing the isolation of the $Q U T R$ repressor gene. The single constitutive strain recovered among revertants of qutA mutants proved due to a novel unlinked mutation, and the apparent absence of constitutive mutations at the QUTA gene locus, also found for the corresponding locus in $N$. crassa (Giles et al., 1985), remains a tantalizing puzzle. Among several interpretations of this observation we note the possibility that the QUTA gene product is unable to induce enzyme formation when acting alone and requires a particular conformational state of the QUTR gene product as a co-activator.

The similarities and differences between the $Q U T$ gene cluster in $A$. nidulans and the $Q A$ cluster in $N$. crassa are fascinating. The opportunity is close at hand for a detailed comparison of the molecular organization of the cluster (A. R. Hawkins and others, unpublished) and of the QUTA activator protein (Beri et al., 1987) in $A$. nidulans with the cluster and $Q A-1 F$ activator protein in $N$. crassa (Giles et al., 1985 and personal communication).

We are grateful to Dr P. Avery for statistical analysis, and thank Dawn Coverly for mapping data collected in the course of her third year undergraduate project and Irene Stobbs for producing the manuscript. The work has been supported by SERC Grant GR/D/1952.0.

\section{REFERENCES}

Armitt, S., McCullough, W. \& Roberts, C. F. (1976). Analysis of acetate non-utilizing (acu) mutants in Aspergillus nidulans. Journal of General Microbiology 92, 263-282.

BAKER, R. J. \& NELDER, J. A. (1978). The GLIM System: Release 3. Oxford: Numerical Algorithms Group.

Beri, R. K., Whittington, H., Roberts, C. F. \& HAWKINS, A. R. (1987). Isolation and characterization of the positively acting regulatory gene $Q U T A$ from Aspergillus nidulans. Nucleic Acids Research 15, 7991-8001.

Case, M. E. \& Giles, N. H. (1975). Genetic evidence on the organisation and action of the $q a-I$ gene product; a protein regulating the induction of three enzymes in quinate catabolism in Neurospora crassa. Proceedings of the National Academy of Sciences of the United States of America 72, 553-557.

Charles, I. G., Keyte, J. W., Brammar, W. J. \& HAWKINS, A. R. (1985). Nucleotide sequence encoding the biosynthetic dehydroquinase function of the pentafunctional $A R O M$ locus of Aspergillus nidulans. Nucleic Acids Research 13, 8119-8128.

Charles, I. G., Keyte, J. W., Brammar, W. J., Smith, M. \& Hawkins, A. R. (1986). The isolation and nucleotide sequence of the complex $A R O M$ locus of Aspergillus nidulans. Nucleic Acids Research 14, 2201-2213.

Francisco Da Silva, A. J., Whittington, H. A., Clements, J. M., Roberts, C. F. \& HaWkins, A. R. (1986). Sequence analysis and transformation by the catabolic 3-dehydroquinase (QUTE) gene from Aspergillus nidulans. Biochemical Journal 240, 481488.

Giles, N. H., Case, M. E., Partridge, C. W. H. \& AHMED, S. I. (1967a). A gene cluster in Neurospora crassa coding for an aggregate of five aromatic biosynthetic enzymes. Proceedings of the National Academy of Sciences of the United States of America 58, 1453-1460.

Giles, N. H. G., Partridge, C. W. H., Ahmed, S. I. \& CASE, M. E. $(1967 b)$. The occurrence of two dehydroquinases in Neurospora crassa, one consitu- tive and one inducible. Proceedings of the National Academy of Sciences of the United States of America 58 1930-1937.

Giles, N. H. G., Case, M. E., Baum, J., Geever, R., Huiet, L., Patel, V. \& Tyler, B. (1985). Gene organization and regulation in the ga (quinic acid) gene cluster of Neurospora crassa. Microbiological Reviews 49, 338-358.

Hawkins, A. R. (1987). The complex Arom locus of Aspergillus nidulans: evidence for multiple gene fusions and convergent evolution. Current Genetics 11, 491-498.

Hawkins, A. R., Giles, N. H. \& Kinghorn, J. R. (1982). Genetical and biochemical aspects of quinate breakdown in the filamentous fungus Aspergillus nidulans. Biochemical Genetics 20, 271-286.

Hawkins, A. R., Francisco Da Silva, A. J. \& RoBERTS, C. F. (1984). Evidence for two control genes regulating expression of the quinic acid utilization ( $Q U T$ ) gene cluster in Aspergillus nidulans. Journal of General Microbiology 130, 567-574.

Hawkins, A. R., Francisco Da Silva, A. J. \& ROBERTS, C. F. (1985). Cloning and characterization of the three enzyme structural genes $Q U T B, Q U T C$ and $Q U T E$ from the quinic acid utilization gene cluster in Aspergillus nidulans. Current Genetics 9, 305-311.

Huiet, L. (1984). Molecular analysis of the Neurospora $q a-1$ regulatory region indicates that two interacting genes control qa gene expression. Proceedings of the National Academy of Sciences of the United States of America 81, 1174-1178.

KINGHORN, J. R. \& Hawkins, A. R. (1982). Cloning and expression in Escherichia coli $\mathrm{K} 12$ of the biosynthetic dehydroquinase function of the arom cluster gene from the eukaryote Aspergillus nidulans. Molecular and General Genetics 186, 145-152.

Pall, M. L. (1981). Adenosine 3',5'-phosphatase in fungi. Microbiological Reviews 45, 462-480.

Partridge, C. W. H., Case, M. E. \& Giles, N. H. (1972). Direct induction in wild-type Neurospora crassa of mutants $\left(q a-1^{c}\right)$ constitutive for the catabolism of quinate and shikimate. Genetics 72, 411-417. 
Patel, V. B., Schweizer, M., Dykstra, C. C., Kushner, S. R. \& Giles, N. H. (1981). Genetic organizational regulation in the $Q A$ gene cluster of Neurospora crassa. Proceedings of the National Academy of Sciences of the United States of America 78, 5783-5787.
Whittington, H. A., Francisco Da Silva, A. J., Grant, S., Roberts, C. F., Lamb, H. \& Hawkins, A. R. (1987). Identification and isolation of a putative permease gene in the quinic acid utilization ( $Q U T)$ gene cluster of Aspergillus nidulans. Current Genetics 12, 135-139. 